\title{
Um estudo sobre a autorregulação da prática instrumental de músicos instrumentistas
}

\author{
Célia Regina Pires Cavalcanti* \\ (Pesquisadora do grupo "Processos \\ formativos e cognitivos em educação \\ musical" UFPR/CNPq)
}

\section{Resumo}

Neste artigo é apresentado um estudo desenvolvido no âmbito do ensino superior com o objetivo de investigar a autorregulação da prática instrumental fundamentado no referencial teórico de Zimmerman (1989). O delineamento metodológico utilizado foi o estudo de levantamento conduzido por meio de um questionário aplicado a 42 instrumentistas divididos em turmas de $1^{\circ}, 2^{\circ}, 3^{\circ}$ e $4^{\circ}$ ano. Os resultados revelaram que em todas as turmas um percentual aproximado de $50 \%$ ou mais de estudantes demonstrou dificuldades para autorregular sua prática instrumental. Na conclusão, procurou-se enfatizar a ideia de que o músico pode exercer controle sobre a própria aprendizagem e a necessidade de uma investigação mais específica quanto à influência de certas variáveis motivacionais sobre a autorregulação da prática instrumental.

Palavras-chave: prática instrumental; autorregulação; instrumentistas.

\footnotetext{
*Célia Regina Pires Cavalcanti, Bacharel em piano e Especialista em Educação Musical e Ensino Instrumental pela Universidade do Estado de Minas Gerais (UEMG), é mestre em música pela Universidade Federal do Paraná (UFPR). Atualmente, é afiliada ao Programa de Pós-Graduação em Música da UFPR, no qual participa do grupo de pesquisa do CNPq "Processos formativos e cognitivos em educação musical". Atua como musicista e professora.
} 


\section{Introdução}

A prática instrumental faz parte da rotina diária daqueles que desejam adquirir ou manter suas habilidades musicais. No entanto, não basta debruçar-se por tempo indeterminado em uma atividade específica, pois, a quantidade de horas acumuladas não garante por si só um ótimo desempenho. Uma performance instrumental bem sucedida depende também da forma como se conduz as sessões de prática, pois a qualidade deste momento pode interferir diretamente no desempenho do instrumentista (Pearce, 2004).

Mais do que empreender horas em exercícios repetitivos, a prática diária requer disciplina, motivação, estabelecimento de padrões pessoais visando compromisso com as metas almejadas, o que demanda desenvolvimento de competências cognitivas. Portanto, uma sessão de prática consistente envolve planejamento, estabelecimento de metas e estratégias adequadas que possibilitem ao músico a oportunidade de alcançar seus objetivos, assim como, habilidade para diagnosticar falhas e corrigi-las (Woody, 2004).

Nesta perspectiva, o instrumentista deve ter como objetivo equipar-se com ferramentas intelectuais, autocrenças e capacidades regulatórias ou habilidade para organizar e promover a própria aprendizagem. Professores que promovem estas habilidades autorreguladoras entre seus alunos de instrumento estão contribuindo não só para que eles percebam que seu comportamento influencia seu desempenho, mas também para que cada um deles "repense e resgate o seu compromisso pela sua própria aprendizagem" (Costa; Boruchovitch, 2006, p. 102). Neste artigo, portanto, é apresentado um estudo desenvolvido no âmbito do ensino superior com o objetivo de investigar a autorregulação da prática instrumental de músicos instrumentistas aplicando o modelo de Zimmerman (1989) de autorregulação acadêmica. 


\section{Autorregulação da aprendizagem}

Ao deixar a aula de instrumento, o aluno torna-se responsável por conduzir o próprio processo de aprendizagem, pois ele irá determinar quais estratégias serão aplicadas, qual peça será estudada ou até mesmo quando e por quanto tempo irá praticar. Hallam (2001) salienta a necessidade de, desde o início da aprendizagem de um instrumento musical, ensinar o estudante a “aprender a aprender", pois, para a autora, a aquisição deste tipo de competência é tão importante quanto o desenvolvimento de competências auditivas ou motoras e são determinantes para um bom desempenho.

Autorregulação é a capacidade de autoensino, ou seja, ser capaz de preparar, facilitar e controlar a própria aprendizagem, proporcionar feedback e julgamentos quanto aos resultados, fomentar a motivação e a concentração, “diz respeito aos mecanismos que as pessoas usam para controlar o seu próprio processo de aprendizagem" (Galvão, 2006, p. 171). Um aluno autorregulado é aquele que usa estratégias próprias testando continuamente a sua eficácia, sentindo-se motivado a fazê-lo.

A aprendizagem autorregulada pode ser definida como um processo ativo e construtivo no qual aprendizes estabelecem objetivos para si próprios buscando monitorar, regular e controlar sua cognição, motivação e comportamento com o intuito de alcançar estes objetivos (Pintrich, 2000 apud Austin; Berg, 2006). Aprendizes autorregulados participam ativamente da sua aprendizagem ao iniciar e dirigir seus esforços pessoais em busca de conhecimento e habilidades.

Estudos considerando a autorregulação da aprendizagem são relativamente recentes. Na área acadêmica, investigações sobre o assunto começaram em meados de 1980 e vêm sustentando que alguns processos fundamentais, como estabelecimento de metas, automonitoramento, estratégias, autoavaliação e autorreações ocupam um lugar de destaque quando relacionados ao sucesso acadêmico. Zimmerman, Bonner e Kovack (2002) esclarecem que: 
A auto-regulação acadêmica refere-se aos pensamentos, sentimentos e ações aplicados para atingir objetivos educacionais específicos e envolve quatro processos inter-relacionados (modelo cíclico): autoavaliação e monitoramento; identificação de meta e planejamento de estratégias; implementação das estratégias selecionadas e monitoramento da precisão em executá-las; monitoramento da relação entre resultados de aprendizagem e estratégia para obter eficácia (Zimmerman, Bonner e Kovack, 2002 apud Polydoro; Azzi, 2008, p. 159).

De acordo com Zimmerman (1989) três fases cíclicas (ver figura 1) compõem a autorregulação acadêmica. A primeira, chamada de fase antecedente, diz respeito ao estabelecimento dos objetivos que se quer alcançar e precede o processo de aprendizagem. Esta etapa envolve estabelecimento de metas, planejamento, seleção de estratégias, análise da tarefa, motivação pessoal, objetivos de realização, crenças de autoeficácia e a valorização da aprendizagem.

A segunda fase ocorre durante a aprendizagem e chama-se controle do desempenho e caracteriza-se pelo cumprimento dos objetivos estabelecidos na fase anterior. Envolve auto-monitoramento ou auto-observação, autocontrole, concentração e autoinstrução. A terceira e última fase chamada de autorreflexão inclui autoavaliação (autojulgamento), atribuições, autorreações e adaptação. Ela se desenvolve depois da execução da tarefa por meio da autoavaliação dos resultados obtidos relacionando-o com as metas estabelecidas.
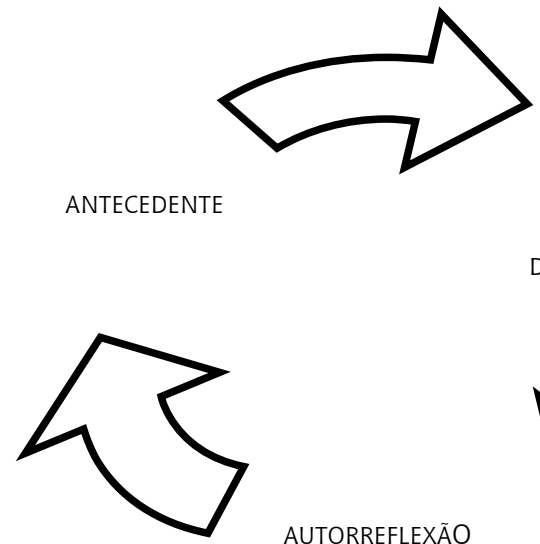

AUTORREFLEXÃO

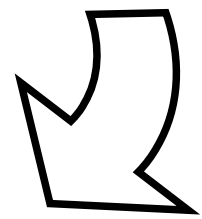

Figura 1 Fases cíclicas que compõem a autorregulação acadêmica. Fonte: Figura elabora pela autora com base em Zimmerman (1989). 
A fase antecedente influencia a fase do controle do desempenho que, por sua vez, exerce influência sobre a fase autorreflexiva. O ciclo está completo quando o processo de autorreflexão influencia também os subprocessos que envolvem a fase antecedente, como resultado, os indivíduos que são bons autorreguladores expandem o seu conhecimento e competências cognitivas (Zimmerman, 1989).

Segundo Merrick (2006) embora um extenso número de pesquisas sobre autorregulação esteja sendo efetuado principalmente no setor da educação (Zimmerman; Kitsantas, 1999; Paris; Paris, 2001), somente na última década tem-se investigado "aprendizagem autorregulada" e "educação musical” por meio de estudos específicos que examinam os fatores relacionados ao ensino e a aprendizagem musical (McPherson, 1993; Nielsen, 1999, 2001, 2004; McPherson; Zimmerman, 2002).

Santiago (2006) relata que "um fator essencial para o estudo instrumental refere-se ao desenvolvimento das habilidades autorregulatórias pelo músico instrumentista", pois a aquisição destas habilidades "são de extrema relevância para o desenvolvimento musical dos instrumentistas, favorecendo o alcance de melhores níveis de performance instrumental" (Santiago, 2006, p. 54, 56).

Portanto, a prática instrumental é uma atividade multifacetada que está incutida na rotina diária dos músicos instrumentistas. No entanto, mais do que envolver-se em uma atividade específica sem refletir sobre ela, uma sessão de prática precisa ser planejada e organizada para que seja produtiva, eficiente e direcionada aos objetivos que se quer alcançar. Prática eficiente relaciona-se com metacognição ou habilidade para organizar e regular a própria aprendizagem, um dos fatores essenciais para a performance (Austin; Berg, 2006; Woody, 2004). 


\section{Apresentação da pesquisa}

Para atingir os propósitos desta pesquisa utilizou-se como delineamento metodológico o estudo de levantamento. Como instrumento de coleta de dados foi elaborado um questionário com 31 itens fundamentados nas três fases cíclicas de autorregulação acadêmica (Zimmerman, 1989; Zimmerman; Cleary, 2006). A população investigada foram alunos regularmente matriculados em curso superior de música, um total de 42 instrumentistas que responderam às perguntas relacionadas à autorregulação da sua prática instrumental. A amostra foi selecionada aleatoriamente dentre a população total de alunos organizada em turmas de $1^{\circ}, 2^{\circ}, 3^{\circ}$ e $4^{\circ}$ ano.

Os itens do questionário foram construídos e organizados nas seguintes subescalas:

1. Planejamento: Planejamento envolve gestão do tempo, isto é, o instrumentista define um tempo específico e organiza o dia ou a semana para realizar suas atividades de aprendizagem, por exemplo: estudar tal obra musical na segunda-feira; na terça, praticar por mais tempo e somente as passagens mais difíceis; na quarta, tocar todo o repertório etc.

2. Metas: O músico estabelece metas com o objetivo de alcançar os resultados desejados. Portanto, o instrumentista pode estabelecer a meta de aperfeiçoar uma habilidade específica, como o uso do pedal, da leitura à primeira vista etc.

3. Estratégias: Estratégias podem ser consideradas como qualquer procedimento adotado para a realização de uma determinada tarefa (Da Silva; Sá, 1997). Algumas estratégias típicas da prática instrumental referem-se ao uso do metrônomo para manter o andamento, anotar o dedilhado, preparar-se fisicamente antes de iniciar os estudos, buscar informações que auxiliem na preparação do repertório na biblioteca ou na internet e realizar uma análise prévia da obra a ser estudada, entre outras.

4. Motivação: Aprender a tocar um instrumento musical exige longos períodos de estudo e de prática instrumental. Desse modo, autorregular o 
comportamento e manter-se motivado torna-se, para o músico, um fator fundamental quando, por exemplo, precisa praticar em dias ou horários que não fazem parte da sua rotina, ou por um tempo indeterminado até aperfeiçoar certa passagem de uma peça musical.

5. Monitoramento: Monitorar as sessões de prática instrumental requer concentração nas metas estabelecidas e autocontrole para supervisionar o estudo, ou seja, envolve atenção seletiva aos aspectos particulares do próprio comportamento ou desempenho.

6. Autoavaliação: Após tocar uma peça do repertório, o aluno avalia o processo e o seu desempenho comparando-o aos objetivos delineados na primeira fase. Portanto, o instrumentista avalia as metas estabelecidas, o progresso do seu estudo e identifica o que é preciso fazer para melhorar. Essa autorreflexão é responsável por desencadear as chamadas reações que podem levar o estudante a continuar persistindo ou desistir da tarefa em função dos resultados da sua autoavaliação.

7. Atribuições: O instrumentista identifica as causas do desempenho, ou seja, as causas do sucesso ou fracasso da performance instrumental. Portanto, após uma avaliação ou um recital, o estudante pode considerar que o sucesso ou fracasso da sua performance está relacionado às próprias habilidades ou a ausência delas.

As respostas relacionadas às subescalas planejamento, metas e estratégias foram avaliadas por meio de uma escala likert de cinco pontos contendo as alternativas: sempre, quase sempre, de vez em quando, raramente e nunca. Os itens do questionário relacionados às subescalas motivação, monitoramento, avaliação e atribuições foram avaliados por meio de uma escala likert de quatro pontos com as alternativas: muita dificuldade, alguma dificuldade, pouca dificuldade e nenhuma dificuldade.

Os dados coletados nas turmas do $1^{\circ}, 2^{\circ}, 3^{\circ}$ e $4^{\circ}$ ano foram analisados, quantificados estatisticamente e considerados por intermédio de uma análise transversal e de uma análise do percentual total dos resultados. 
Fundamentado nos resultados obtidos, a princípio, uma análise descritiva do questionário foi efetuada com o objetivo de visualizar alguns aspectos da pesquisa. Esta análise considerou os resultados correspondentes ao número total de alunos divididos por ano, gênero, idade, tempo de estudo e instrumento. Em uma análise posterior observou-se também os resultados da pesquisa relacionados ao número total de alunos e ao tempo de curso.

Por intermédio de uma análise descritiva observou-se que o maior percentual de respondentes concentrou-se no $1^{\circ}$ ano $(38,1 \%)$, seguido do $2^{\circ}$ ano $(28,8 \%), 3^{\circ}$ ano $(19 \%)$ e $4^{\circ}$ ano $(14,3 \%)$. A distribuição dos estudantes de acordo com o gênero indicou existir uma predominância de estudantes do gênero masculino, 78,8\%. Na distribuição da amostra de acordo com a idade verificouse que o maior percentual dos respondentes, $76,2 \%$, concentrou-se na faixa de menos de 20 a 29 anos. Na variável, tempo que estuda música (meses, anos), os números relevantes mostraram que a maioria dos participantes concentrou-se na faixa de 5 a 14 anos, correspondendo a $69 \%$ do total. No que se refere ao instrumento musical, 38\% eram violonistas seguidos pelos pianistas com 14,3\% e violinistas com $11,9 \%$, perfazendo um total de $64,2 \%$ dos alunos. O restante dos músicos estudava: percussão $(7,1 \%)$, flauta transversal $(7,1 \%)$, trompete $(4,8 \%)$, trompa $(4,8 \%)$, contrabaixo $(4,8 \%)$, violoncelo $(2,4 \%)$, clarineta $(2,4 \%)$ e alaúde $(2,4 \%)$. Portanto, a variável relacionada ao instrumento musical demonstra que $64,3 \%$ dos participantes tocavam violão, violino e piano e $54 \%$ tocavam instrumentos de corda (violão, violino e violoncelo).

Com relação às subescalas apresentadas no questionário a primeira questão apresentada estava relacionada ao planejamento do estudo. Os resultados desta pesquisa demonstraram que $48,83 \%$ do total de alunos responderam que planejavam seu estudo de vez em quando, raramente ou nunca. Por meio da análise transversal verificou-se que no $1^{\circ}$ e $3^{\circ}$ anos concentrou-se o maior percentual de alunos que de vez em quando e raramente ou nunca planejavam seu estudo $-62,8 \%$ e $62,5 \%$, respectivamente $\left(2^{\circ}\right.$ ano $41,7 \%$, e $4^{\circ}$ ano $\left.-16,7 \%\right)$. 
Metas podem ser compreendidas como aquilo que o indivíduo tem em mente cumprir ou atingir (Bzuneck, 2001). Quando à questão relacionada à escolha de metas todos os instrumentistas do $4^{\circ}$ ano responderam que sempre estabeleciam metas com o objetivo de alcançar bons resultados, assim como, $75 \%$ do $3^{\circ}$ ano, $66,7 \%$ do $2^{\circ}$ ano e $62,6 \%$ do $1^{\circ}$ ano. Estes resultados indicaram que à medida que avançam no curso os estudantes estabelecem metas com mais frequência. Portanto, ao verificar o percentual total de respondentes, 72,09\% sempre ou quase sempre estabelecem metas.

Diante de uma nova peça para estudar o instrumentista pode encontrar certos desafios, despender mais tempo e esforço por não utilizar estratégias adequadas. Com relação à escolha de estratégias esta pesquisa demonstrou que 83,3\% dos músicos do $4^{\circ}$ ano sempre e quase sempre consideram a utilização de estratégias para a realização de uma determinada tarefa, seguidos por $91,7 \%$ do $2^{\circ}$ ano, $87,6 \%$ do $1^{\circ}$ ano e $75 \%$ dos instrumentistas do $3^{\circ}$ ano. Portanto, dos 42 participantes $83,72 \%$ sempre ou quase sempre selecionam estratégias que o auxiliem no processo de aprendizagem.

Outra subfunção da autorregulação refere-se à motivação. Quando precisam estudar em dias ou horários que não fazem parte da rotina, 83,35\% dos instrumentistas do $4^{\circ}$ ano, $62,5 \%$ do $3^{\circ}$ ano, $58,3 \%$ do $2^{\circ}$ ano e $56,2 \%$ do $1^{\circ}$ ano encontram alguma ou muita dificuldade. Levando-se em consideração o número total de alunos, 55,81\% encontram alguma ou muita dificuldade para praticar nestas circunstancias. Para manter-se motivado a praticar mesmo quando não gosta da peça musical que está estudando, 100\% dos instrumentistas do $3^{\circ}$ ano, $68,7 \%$ do $1^{\circ}$ ano, $50 \%$ do $4^{\circ}$ ano e $41,6 \%$ do $2^{\circ}$ ano responderam que sentem alguma ou muita dificuldade para executar a tarefa. Portanto, ao analisar as respostas em percentuais pelo número total de estudantes, 76,74\% percebem que encontram muita ou alguma dificuldade para praticar quando não gostam do repertório que estão tocando.

No processo de autorregulação, durante suas sessões de prática, o instrumentista monitora seu comportamento. Ele permanece atento aos procedimentos adotados, substitui estratégias, concentra-se em suas metas 
observando se está caminhando em direção aos seus objetivos e corrige possíveis falhas. Dos instrumentistas, $87,5 \%$ do $3^{\circ}$ ano, $75 \%$ do $2^{\circ}$ ano, $50 \%$ do $1^{\circ}$ ano e $33,3 \%$ do $4^{\circ}$ ano responderam que encontram alguma ou muita dificuldade em monitorar sua prática instrumental mantendo-se concentrado em suas metas, perfazendo um percentual de $60 \%$ do total de músicos instrumentistas.

A autoavaliação é a subfunção da fase de autorreflexão e ocorre após a performance. Quanto à questão relacionada à avaliação das metas estabelecidas e sua contribuição para o desempenho do instrumentista, $37,5 \%$ dos estudantes do $3^{\circ}$ ano, $25 \%$ do $1^{\circ}$ ano, $16,6 \%$ do $2^{\circ}$ ano e $16,6 \%$ do $4^{\circ}$ ano responderam que se deparam com alguma ou muita dificuldade para fazer essa avaliação. Sendo assim, um percentual de $79 \%$ do total de participantes não encontrou qualquer tipo de dificuldade nesse item.

Para avaliar as causas do seu desempenho $18,7 \%$ de músicos do $1^{\circ}$ ano, $16,6 \%$ do $2^{\circ}$ ano, $16,6 \%$ do $4^{\circ}$ ano e $12,5 \%$ do $3^{\mathrm{a}}$ ano responderam que sentem alguma ou muita dificuldade nessa questão. Portanto, um percentual de $83 \%$ do total de estudantes se depara com pouca ou nenhuma dificuldade para atribuir causas ao seu desempenho.

Por meio da análise dos resultados pode-se observar que $01^{\circ}$ ano, em relação às outras turmas, apresentou um percentual maior de músicos que, de vez em quando, raramente ou nunca planejam o estudo, estabelecem metas, escolhem estratégias adequadas ou encontram alguma ou muita dificuldade para atribuir causas ao seu desempenho. No entanto, por meio de análise transversal, verificou-se que o $3^{\circ}$ ano também apresentou um percentual elevado de alunos que de vez em quando, raramente ou nunca planejam o estudo ou encontram alguma ou muita dificuldade para monitorar sua prática. Eles mantêm-se concentrados em suas metas, seja para avaliar as metas estabelecidas, seja para se manter motivados diante dos desafios inerentes à aprendizagem do instrumento musical.

Com relação à questão apresentada sobre o planejamento do estudo, os alunos do $2^{\circ}$ ano, $41,7 \%$, de vez em quando, raramente ou nunca planejam o estudo e $75 \%$ encontram alguma ou muita dificuldade para 
monitorar sua prática instrumental. Os alunos do $4^{\circ}$ ano demonstraram que encontram alguma ou muita dificuldade em uma das questões relacionadas à motivação, pois, $83,35 \%$ sentem que é um desafio praticar em dias ou horários que não fazem parte da sua rotina.

Portanto, os resultados revelaram que em todas as turmas um percentual considerável de instrumentistas demonstrou dificuldade para autorregular sua prática instrumental em alguma fase do processo de autorregulação.

\section{Conclusão}

O músico instrumentista pode tornar-se participante ativo e adquirir autonomia sobre todos os aspectos que envolvem a autorregulação da sua prática instrumental ao estabelecer cursos de ação adequados, ao motivar e controlar todo o procedimento. As habilidades autorreguladoras promovem o engajamento cognitivo, possibilitam uma performance de melhor qualidade (Bandura, 2001) e estimulam uma participação ativa no próprio processo de aprendizagem. Compreender e aplicar o processo de autorregulação pode

84 significar uma prática instrumental mais eficiente e, consequentemente, um melhor desempenho.

Os resultados desta pesquisa demonstraram que os pontos críticos no processo de autorregulação da prática instrumental dos participantes foram o planejamento do estudo, as questões correspondentes à motivação e ao monitoramento dos procedimentos relacionados à prática instrumental. Ao planejar o estudo e estabelecer metas, o instrumentista precisa escolher estratégias adequadas que o auxiliem a cumprir seus objetivos. Neste processo, deve ainda monitorar e, em seguida, avaliar o impacto dessas metas sobre os resultados da sua performance, o que resultará em um sentimento de satisfação ou insatisfação que influenciará os procedimentos subsequentes a serem adotados. Ou seja, a avaliação modifica o planejamento e este, por sua vez, modifica a forma de executar a tarefa. 
Quando o aluno de instrumento estabelece um plano de estudo, mas não acompanha suas metas ou avalia os resultados do seu desempenho ao refletir sobre os procedimentos e estratégias de aprendizagem adotadas, o processo de autorregulação é interrompido. No contexto acadêmico, o estudante seleciona atividades que, segundo prevê, acredita que possa executar e então abandona outros objetivos ou cursos de ação por não acreditar que possa implementá-los (Bzuneck, 2002).

Vários fatores podem influenciar a continuidade dos procedimentos implícitos na autorregulação da prática instrumental. Entre eles, destacam-se as variáveis motivacionais que estimulam ou não o desempenho da ação e contribuem de forma positiva ou negativa para efetivar todo o processo, determinando o grau de autorregulação apresentado pelos alunos. A autoavaliação que os estudantes fazem de suas capacidades (crenças de autoeficácia) e o valor que atribuem à atividade ou tarefa a ser realizada, são alguns dos fatores que influenciam e promovem o comportamento autorregulado. Futuras pesquisas podem contemplar um estudo mais aprofundado e específico sobre os aspectos motivacionais que envolvem a autorregulação e a prática instrumental.

Para finalizar, deve-se considerar que somente a intenção não basta para causar as transformações necessárias em função de uma prática instrumental mais eficiente. Portanto, o instrumentista pode exercer controle sobre a própria aprendizagem ao aplicar o processo de autorregulação em sua prática diária e, assim, direcionar intencionalmente o seu comportamento aos objetivos que espera alcançar.

\section{Referências}

AUSTIN, J. BERG, M. H. Exploring music practice among sixth-grade band and orchestra students 2006 Disponível em: <http://pom.sagepub.com/cgi/content/abstract/34/4/535>. Acesso em: 06 jan. 2008. 
BANDURA, A. Social Cognitive Theory: An Agentic. Annual Reviews Psychologist, v. 52, p. 1-26, 2001. Disponível em: <http://www.des.emory.edu/mfp/selfefficacy. html>. Acesso em: 14 mar. 2007.

BZUNECK, J. A. As crenças de autoeficácia e seu papel na motivação do aluno. In: BORUCHOVITCH, E. ; BZUNECK, J. A. (Orgs.). A motivação do aluno: contribuições da psicologia contemporânea. 2.ed. Petrópolis: Vozes, 2002. p. 116-133.

COSTA, E. R.; BORUCHOVITCH, E. Autoeficácia e a motivação para aprender: considerações para o desempenho escolar dos alunos. In: AZZI, R. G.; POLYDORO, S. A. J. (Orgs). Autoeficácia em diferentes contextos. São Paulo: Alinea, 2006. p. 87-109.

DA SILVA A. L.; SÁ, L. Saber estudar e estudar para saber. In: BORUCHOVITCH, E. Estratégias de aprendizagem e desempenho escolar: considerações para a prática educacional. Psicol. Reflex. Crit., Porto Alegre, v. 12, n. 2, 1999.

GALVÃO. A. Cognição, Emoção e Expertise Musical. Psicologia: Teoria e Pesquisa, Brasília, v. 22, n. 2, p. 169-174, ago. 2006.

HALLAM, S. The Development of Metacognition in Musicians: Implications for Education. British Journal of Music Education, v. 18, issue 1, p. 27-39, 2001.

MERRICK, B.M. The relationship between self-efficacy and self-regulated behavior within a secondary school music technology based creative learning environment. 2006. Disponível em: <www.library.unsw.edu.au/ thesis/adt-NUN/uploads/approved/adt-UN100 60801.224059/ public/01 front.pdf>. Acesso em: 04 mar. 2008.

PEARCE, E. T. Self-directed practice: the key to both student success and motivation. The American Music Teacher, v. 54, n. 2, p. 29-30, 2004.

POLYDORO, S. A. J.; AZZI, R. G. Autorregulacao: aspectos introdutórios. In: BANDURA; AZZI; POLYDORO. Teoria Social Cognitiva: conceitos básicos. Porto Alegre: Artmed, 2008. p. 43-67.

SANTIAGO, P. A integração da prática deliberada e da prática informal no aprendizado da música instrumental. Per musi, Belo Horizonte, n. 13, p. 52-62, 2006.

WOOD, R.H. The motivation of exceptional musicians. Music Educators Journal, v. 90, n. 3 , p. 17-21, 2004.

ZIMMERMAN, B.J. A social cognitive view of self-regulated academic learning. Journal of Educational Psychology, v. 81, issue 3, september 1, 1989.

ZIMMERMAN, B. J.; CLEARY, T. J. Adolescents' development of personal agency: the role of self-efficacy beliefs and self- regulatory skill. In: PAJARES, F.; URDAN, T. Self-efficacy beliefs of adolescents. Greenwich, CT: Information Age Pubishing, 2006. p. 45-69.

E-mail: celiarpcavalcanti@yahoo.com.br

Artigo recebido e aprovado em 08/11/2010. 